\title{
Influence of gravity on eutectic BiSn samples solidified by the vertical Bridgman method
}

\author{
Rafael Cardoso Toledo*, Chen Ying An, Irajá Newton Bandeira \\ Instituto Nacional de Pesquisas Espaciais - INPE, São José dos Campos, SP, Brazil \\ *toledo.rc@gmail.com
}

Keywords: Bridgman Method; Eutectic Alloy; Convective Flows

\section{Abstract}

Composition profiles of the eutectic Bismuth-Tin alloy (Bi43Sn57 at\%) solidified by regular and inverted vertical Bridgman methods are presented, and the study of the influence of the gravity on the solute alloy redistribution is made. The inverted vertical Bridgman method (IVB), where the solidification occurs from the top to the bottom of the melt, allows to set-up an opposite solutal and thermal configuration from that of the regular vertical Bridgman (VB) method. The samples were analyzed by densitometry and scanning electron microscopy (SEM).

Introduction
Solidification behavior and structural
characteristics of eutectic alloys in many systems
arouse the interest because of their influence on the
properties and performance of materials containing
eutectic constituents. Eutectic alloys are important to
materials engineering, leading to extensive
theoretical and experimental study of the
relationship between microstructure and
solidification conditions. In the process of
solidification of eutectic alloys, thermal convection
plays a very important role by affecting heat and
mass transfer and therefore the solute distribution.
Instabilities of the flow in the melt can cause the
appearance of temperature oscillations and
influence the interface velocity. This in turn can lead
to morphological instabilities of the plane front during
directional solidification. In addition, asymmetric flow
patterns can lead to an inhomogeneous structure of
the sample [1-19].
The bismuth-tin alloy is mainly used as low
melting point solder alloys (below 200 ${ }^{\circ} \mathrm{C}$ ) in
electrical and electronic equipment and from the
2000's on, has been an important substitute for
welding alloys containing toxic materials. The low
eutectic temperature avoids thermal damages during
the assembly process of microelectronic
components. However, utilization of Bi-Sn solder is
limited by unsatisfactory junction strength due to the
brittle nature of the Bi-rich phase and thick interfacial
intermetallic layer. It is thus essential to modify the
microstructure and improve the mechanical

properties of Bi-Sn solder to achieve satisfactory reliability for more applications [20-21].

The objective of this work is aimed to study the influence of the gravity on the redistribution of solute during the solidification process by the vertical Bridgman method (regular and inverted).

\section{Experimental}

The experimental system consists of a resistive furnace, temperature controller, speed controller and stepping motor. The solidification experiments were carried out in the vertical furnace in accordance with the scheme and the thermal profile as shown in Figure 1.

The eutectic $\mathrm{Bi}_{43} \mathrm{Sn}_{57}$ (at \%) alloy was prepared from purified bismuth (99.999\%) and tin (99.9999 $\%)$. A mass of $20.0 \mathrm{~g}$ of the alloy was placed into a quartz tube with an $8 \mathrm{~mm}$ diameter and $15 \mathrm{~mm}$ length. The quartz tube was sealed at a pressure of $10^{-6}$ Torr. The furnace was heated to $250{ }^{\circ} \mathrm{C}$, yielding a temperature gradient of $14^{\circ} \mathrm{C} / \mathrm{cm}$ for VB and $6^{\circ} \mathrm{C} / \mathrm{cm}$ for IVB along the sample at the estimated position of solid-liquid interface. Solidification was carried out using a stepping motor to move the quartz ampoule through the furnace at $0.75 \mathrm{~mm} / \mathrm{h}$.

After solidification, the sample was cut into several discs and their compositions were measured by densitometry method in order to determine the axial solute distribution versus solidified fraction (fs). The other similar sample was cut in the longitudinal direction and its structure morphologies were examined using an electronic microscope JEOL/SEM model 5310. 
Classical Vertical Bridgman

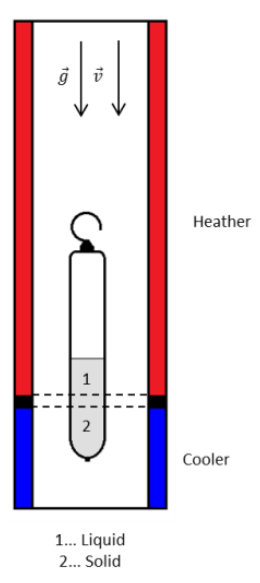

(a)

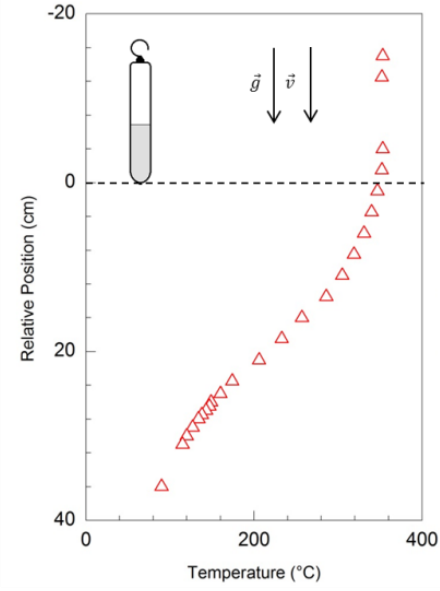

(b)

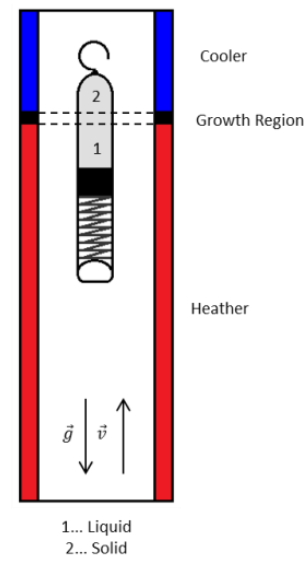

(c)
Inverted Vertical Bridgman

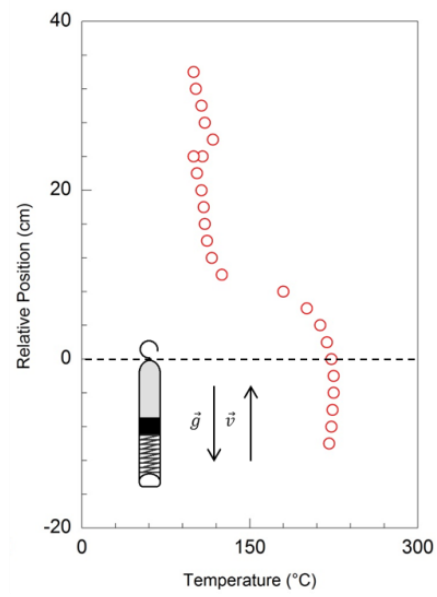

(d)

Figure 1. (a) Schematic diagram of vertical Bridgman (VB); (b) Thermal profile of the solidification furnace for VB; (c) Schematic diagram of inverted vertical Bridgman (IVB), where the quartz ampoule has an internal metal spring and a graphite plunger in order to hold the melt at the upside down position. (d) Thermal profile of the solidification furnace for IVB.

\section{Results and discussion}

Eutectic alloys composed of a metallic phase and a semiconductor phase generally have a complex regular or irregular structure [22-23]. In the complex regular structure one observes two types of regions: one zone of a repeating regular pattern and other zone of random orientation. In the case of $\mathrm{Bi}-\mathrm{Sn}$ system, a complex regular microstructure can be obtained by using directional solidification, and an ideal coupled eutectic alloy is formed only by Bi-rich and the Sn-rich solid solutions.

Figure 2 and 3 shows, respectively, the graphics of the density and solute composition versus solidified (by VB and IVB) fraction for $\mathrm{Bi}_{43} \mathrm{Sn}_{57}$ (at \%) alloy, determined by the densitometry technique [2426].

In the solidification of the Bi-Sn eutectic alloy, the solute (bismuth, $9.80 \mathrm{~g} / \mathrm{cm}^{3}$ ) is heavier than the solvent (tin, $7.31 \mathrm{~g} / \mathrm{cm}^{3}$ ) which results in a stable solutal gradient on the liquid side of the interface during the BV and an unstable configuration in the case of IVB. A composition outside the eutectic range usually grows primary dendrites followed by the eutectic interface. Thus, the growth of dendrites of solute is more favorable during the VB process [27].

It is observed in Figure 2 and 3 that the density and solute values are nearer to their nominal values of $8,56 \mathrm{~g} / \mathrm{cm}^{3}$ and 43 at $\%$ of $\mathrm{Bi}$, respectively, along the length $(0.25<\mathrm{fs}<0.75)$ of the sample solidified by the IVB method. For this solidification set-up, both composition and temperature are unstable, but, on other hand, is favorable to obtain an alloy with more homogeneous axial composition. The solidification direction is anti-parallel to the gravity vector under a destabilizing thermal gradient, and the stratification effects can be reduced by the buoyancy driven convection flows in the melt.

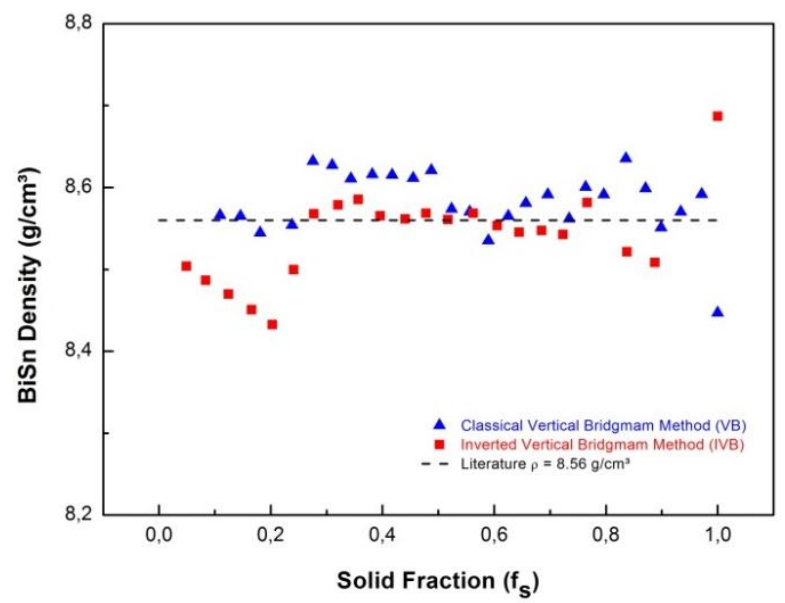

Figure 2. Average density of BiSn eutectic alloys as function of the solidified fraction (fs). 


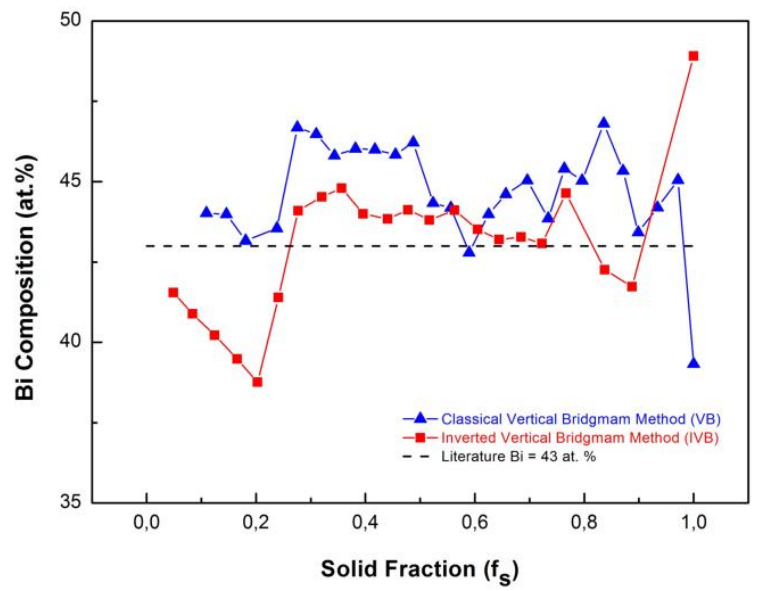

Figure 3. Bismuth composition profile for VB and IVB BiSn eutectic alloy analyzed by densimetric technique.

Figure 4 and 5 shows the images, obtained by electron backscattering, of the samples solidified by VB. It is observed the presence of two eutectic phases: an $\alpha$ phase rich in Bi (light gray color) and a $\beta$ phase rich in Sn (dark gray color). Dendritic structures were observed only in the radial analysis of the samples.

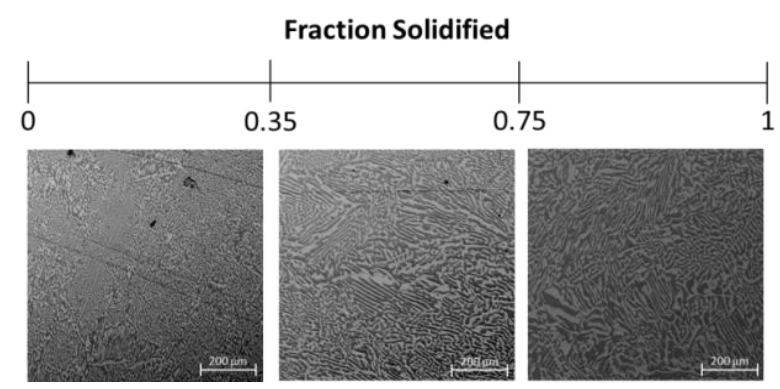

Figure 4. SEM images of the longitudinal direction analysis of the eutectic BiSn obtained by VB.

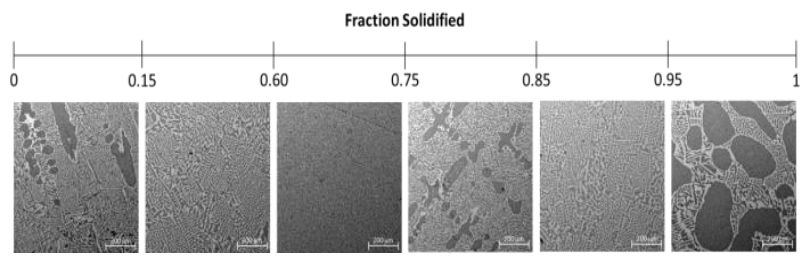

Figure 5. SEM images of the radial direction analysis of the eutectic BiSn obtained by VB.

In Figure 4, were observed complex regular structures with variation of the thickness of the phases along the length of the sample. However, in
Figure 5, were observed dendritic structures (in the $\beta$ phase) plus irregular eutectic structures at the beginning of the samples (fs $<0.15$ ), eutectic complex regular structures in the range of $0.15<\mathrm{fs}$ $<0.60$, eutectic irregular structures in the range of $0.60<\mathrm{fs}<0.75$, dendritic structures (in the $\beta$ phase) plus irregular eutectic structures in the range of 0.75 $<$ fs $<0.85$, eutectic irregular structures in the range of $0.85<$ fs $<0.95$ and dendritic structures (in the $\beta$ phase) plus irregular eutectic structures in the remainder of the sample (fs $>0.95$ ).

Figure 6 and 7 shows the images, obtained by electron backscattering, of the samples solidified by IVB. It is observed the presence of two eutectic phases: an $\alpha$ phase rich in $\mathrm{Bi}$ (light gray color) and a $\beta$ phase rich in Sn (dark gray color).

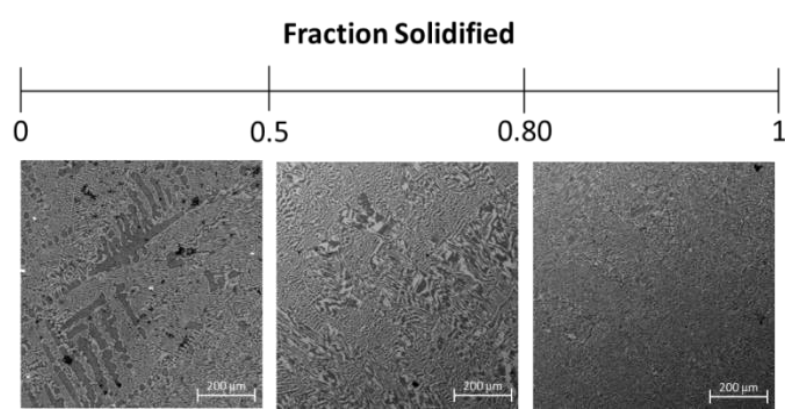

Figure 6. SEM images of the longitudinal direction analysis of the eutectic BiSn obtained by IVB.

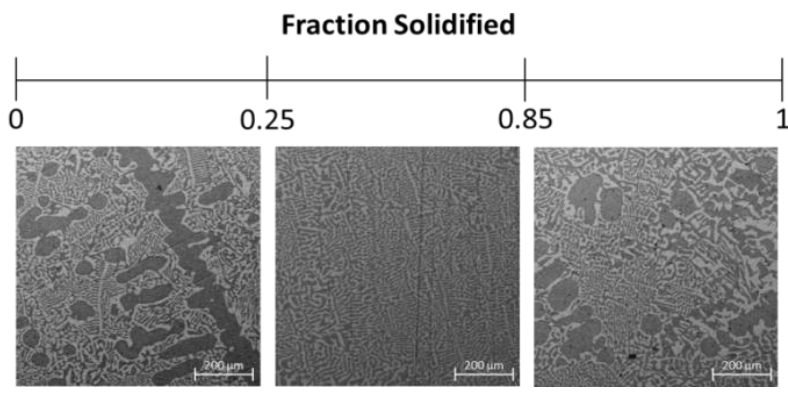

Figure 7. SEM images of the radial direction analysis of the eutectic BiSn obtained by IVB.

In Figure 6, were observed dendritic structures (in the $\beta$ phase) plus irregular eutectic structures in the first half of the length of the samples (fs $<0.50$ ) and complex regular structures with variation of the thickness of the phases along the length of the sample. However, in Figure 7, were observed dendritic structures (in the $\beta$ phase) over irregular eutectic structures at the beginning (fs $<0.15$ ) and 
the end (fs $>0.85$ ) of the samples and eutectic complex regular structures in the remainder of the sample $(0.25<$ fs $<0.85)$.

\section{Conclusion}

For regular Bridgman method, because of the existence of a stable solutal gradient caused by the heavier solute $(\mathrm{Bi})$, the solidification of $\mathrm{Bi}_{43} \mathrm{Sn}_{57}$ (at $\%$ ) alloy occurs far away from eutectic composition, which results in the presence of primary phase and dendritic structure. On the other hand, the presence of buoyancy driven convection flows in the melt, caused by a destabilizing thermal gradient during the inverted Bridgman method, allows to homogenize the liquid alloy near the ideal eutectic composition.

\section{Acknowledgments}

The authors are grateful to the CAPES for the financial support.

\section{References below}

1 M. C. Flemings (1974) Solidification processing. Mc Graw Hill, NewYork

2 R. Elliott (1983) Eutectic solidification processing crystalline and glassy alloys. Butterworths, Guilford, UK

3 E. Çadırlı, H. Kaya, M. Gündüz (2007) Directional solidification and characterization of the Cd-Sn eutectic alloy, Journal of Alloys and Compounds 431:171-179.

4 E. M. Monberg, W. A. Gault, F. Simchock, F. Domingguez (1987) J. Crystal Growth 83:174

5 K. Hoshikawa, H. Nakanishi, H. Kohda, M. Sasaura (1989) J. Crystal Growth 94:643

6 E. Semma, V. Timchenko, M. El Ganaoui,E. Leonardi (2005) The effect of wall temperature fluctuations on the heat transfer and fluid flow occurring in a liquid enclosure, International Journal of Heat and Fluid Flow 26:547-557

7 J. D. Verhoeven, R. H. Homer (1970) Met. Trans. 1:3437

8 J. M. Quenisset, R. Naslain (1981) J. Crystal Growth 54:465

9 V. Baskaran, W. R. Wilcox (1984) J. Crystal Growth 343

10 S. Chandrasekhar, G. F. Eisa, W. R. Wilcox (1986) J. Crystal Growth 76:485

11 J. M. Quenisset, R. Sokolowski, M. E. Glicksman (1983) J. Crystal Growth 63:389

12 J. Z. Jin, K. F. Kobayashi, P. H. Shingu (1984) Metall. Trans. 15A:307

13 C. Y. An, I. N. Bandeira, A. H. Franzan, S. Eleutério Filho, M. R. Slomka (1993) The influence of gravity on Pb1-xSnxTe crystals grown by the vertical bridgman method. In: L. L. Regel, W. R. Wilcox (Ed.). Materials Processing in High Gravity. -. Potsdam, New York: Plenum Press, pp 95-100

14 R. Bennacer, M. El Ganaoui, E. Leonardi (2006) Symmetry breaking of melt flow typically encountered in a Bridgman configuration heated from below, Applied Mathematical Modelling 30:1249-1261

15 J. D. Verhoeven, J. T. Mason, R. Trivedi (1986) The effect of convection on the dendrite to eutectic transition. Metallurgical Transactions A 17A:991-1000

16 H. Sprenger, H. Richter, J. J. Nickl (1976) Unidirectional solidification of Ni-Mo-Al eutectic alloys, Journal of Materials Science doi: 10.1007/PL00020335
17 M. J. Suk, I. S. Ahn, I. H. Moon (1986) The microstructure of unidirectionally solidified Ag-Ge eutectic alloys, Journal of Materials Science doi: 10.1007/BF01145508

18 J. -Z. Li, M. Kaya, R. W. Smith (1994) Modification of $\gamma$-(Fe, Cr)3C pseudo-binary eutectic, Journal of Materials Science doi: 10.1007/BF00351435

19 Y. Wang, H. Jones, P.V. Evans (1998) Eutectic solidification characteristics of Bridgman grown AI-3Fe-0.1V alloy, Journal of Materials Science doi: 10.1023/A:1004483904519

20 The European Parliament and of the Council of the European Union (2003) Directive 2002/95/EC of the european parliament and of the council of 27 January 2003 on the restriction of the use of certain hazardous substances in electrical and electronic equipment. Official Journal of the European Union, L 037, 13/02/2003 pp 19-23

21 J. Wang, H. Wei, P. He, T. Lin, F. Lu (2015) Microstructure and mechanical properties of tin-bismuth solder reinforced by aluminum borate whiskers. Journal of Electronic Materials doi: 10.1007/s11664015-3896-0

22 J. D. Verhoeven (1989) Fundamentals of physical metallurgy. John Wiley \& Sons - New York.

23 J. A. Dantzing, M. Rappaz (2009) Solidification. CRC Press London.

24 C. Y. An, I. N. Bandeira, D. M. Rowe, G. Min (1994) An exact density formula for substitutional solid solution alloys. Jounal of Materials Science Letters 13:1051-1053

25 R. C. Toledo (2013) Study of solidification of eutectic alloys in microgravity environment, PhD Thesis, INPE http://sid.inpe.br/mtcm19/2013/02.21.12.26. Accessed 18 November 2013

26 R. C. Toledo, C. Y. An, I. N. Bandeira, F. E. de Freitas (2016) The influence of gravity on eutectic pbsn alloy grown by the vertical bridgman method. Materials Science Forum, 869: 637-642 doi: 10.4028/www.scientific.net/MSF.869.637

27 J. D. Verhoeven, J. T. Mason, R. Trivedi (1986) The effect of concection on the dendrite to eutectic transition. Metallurgical Transactions A, 17A: 991-1000 